\title{
Efficiency and Labor Market Dynamics in a Model of Labor Selection *
}

\author{
Sanjay K. Chugh ${ }^{\dagger}$ \\ Boston College \\ Kiel Institute for the World Economy \\ Christian Merkl ${ }^{\ddagger}$ \\ Friedrich-Alexander-University Erlangen-Nuremberg \\ Kiel Institute for the World Economy \\ IZA Institute
}

First Draft: September 2010

This Draft: April 9, 2013

\begin{abstract}
We characterize efficient allocations and cyclical fluctuations in a labor selection model. Potential new hires are heterogenous in the cross-section in their degree of training costs. In a calibrated version of the model that identifies costly selection with micro-level data on training costs, efficient fluctuations feature highly volatile unemployment and hiring rates, in line with empirical evidence. We show analytically in a partial equilibrium version of the model that volatility arises from selection effects, rather than general equilibrium effects.
\end{abstract}

Keywords: labor market frictions, hiring costs, efficiency, amplification

JEL Classification: E24, E32, J20

\footnotetext{
${ }^{*}$ We thank Susanto Basu, Ryan Chahrour, Timothy Fuerst, Veronica Guerrieri, Joseph Kaboski, Wolfgang Lechthaler, Guido Lorenzoni, Steven Lugauer, Michael Pries, Chris Reicher, and Henning Webber for useful feedback. Christian Merkl thanks the Fritz Thyssen foundation for financial support during his visit at the National Bureau of Economic Research where the project was initiated. Ana Lariau has provided brilliant research assistance. We received helpful comments at presentations at the 2011 SED Meetings, the German Economic Association, Sveriges Riksbank, the Federal Reserve Bank of Cleveland, the Ifo Macro Seminar, the Boston College Macro Lunch Workshop, the University of Notre Dame, and the Kiel Institute.

${ }^{\dagger}$ Corresponding author. Email: sanjay.chugh@bc.edu.

${ }^{\ddagger}$ Email: christian.merkl@wiso.uni-erlangen.de.
} 


\section{Introduction}

The central idea of the model we build is purposeful selection of a subset of applicants. This aspect of labor markets is realistic and has not been much emphasized in macro-labor analysis. Selection as an important margin of adjustment in firms' hiring decisions is a long-standing idea. An early important empirical firm-level contribution was Barron, Bishop, and Dunkelberg (1989), who adopt and find strong evidence for the view that "...most employment is the outcome of an employer selecting from a pool of job applicants..." due to cross-sectional heterogeneity in the pool of applicants. Davis, Faberman, and Haltiwanger (2013) add further evidence to the view that, in their terminology, "hiring standards" play an important role among the many margins of labor adjustment. Selection issues seemingly would be an important component of hiring standards. Anecdotal evidence also suggests that margins besides the traditionally focused-upon vacancy margin may have become more important in recent years. ${ }^{1}$

Cross-sectional heterogeneity amongst potential new workers can arise along many dimensions. Explicit micro-level evidence exists on the cross section of training costs for new hires, in contrast to other potential sources of heterogeneity. Cross-sectional training costs is the one dimension on which we thus focus, which has the advantage that our aggregate model can be calibrated to target data measured directly at the firm level. Barron, Black, and Loewenstein (1989), and others who have followed their approach, provide evidence of significant cross-sectional heterogeneity in firm-level training costs. Examples of these "temporary" training costs include items such as shadowing other workers to observe how the job is performed, getting to know the culture of the firm, understanding the organization chart, figuring out who to contact about administrative matters, and other such orientation activities. Some new workers will naturally incur higher training costs than others, but these costs last for only a short time and do not affect longer-run characteristics of the worker.

Labor selection along the training cost dimension is the single driving force of long-run and short-run labor market outcomes in our model. We show that the efficient solution of a labor selection model displays sharp amplification on labor market aggregates when driven by standard aggregate total factor productivity (TFP) shocks; the simulated business-cycle statistics in the model are in line with U.S. cyclical data. This solution emerges from a social planning problem, and this result is in marked contrast to that in an efficient version of the labor search and matching model, as Shimer (2005) and the subsequent literature has shown. Importantly, no decentralized wage determination system needs to be imposed on our model, which has been the main thrust of the recent matching literature.

\footnotetext{
${ }^{1}$ A few recent news articles, among others, that raise this point are "Beware the Phantom Job Listing," Wall Street Journal, U.S. Edition, January 8, 2013, "When Being Jobless Is a Barrier to Finding a Job," New York Times, February 18, 2013, and "With Employees to Fill, Employers Wait for Perfection," New York Times, March 7, 2013. The latter articles cites Davis, Faberman, and Haltiwanger (2013).
} 
Training costs and their heterogeneity across potential new hires generate employment surpluses for all new hires, be it the marginal new hire or inframarginal new hires, making long-term employment relationships valuable. Hence, the labor market deviates from a spot market, instead articulating flows between labor-market states. The key parameter of the model is the cross-sectional dispersion of training costs across new hires, which directly affects the efficient threshold training cost for hiring new workers. We base the calibration of this parameter on firm-level data used by Barron, Black, and Loewenstein (1989) and Dolfin (2006). In the calibrated model, aggregate TFP shocks move a large mass of individuals across the endogenously time-varying threshold, hence our use of the term "labor selection."

Focusing the model on selection effects and efficiency allows us to highlight that no other frictions are needed to deliver sharp fluctuations in the labor market, which makes the intuition easy to understand. ${ }^{2,3}$ This focus does not deny that other frictions, be they on quantities or on prices, do not or cannot play an important role in macro-labor dynamics. Extensively studied in the literature are the role of search and matching frictions, along with frameworks such as the involuntary unemployment framework of Christiano, Trabandt, and Walentin (2010), the rigid-wage class of models as in Gali (2011) and Gali, Smets, and Wouters (2011), as well as earlier versions of the labor selection model incorporating New Keynesian pricing frictions and wage setting frictions, such as Lechthaler, Merkl, and Snower (2010). These various models, based on different primitives and distortions, do not disentangle the amplification effects that are due to efficient surplus splitting versus inefficient surplus splitting. The point of our work is to analytically and quantatively analyze efficient allocations in a tractable dynamic selection model, in a way that can be traced all the way back to the early indivisible (and efficient) labor models of Hansen (1985) and Rogerson (1988). Our model and its workings has interpretations in terms of the indivisible labor models of Hansen (1985) and Rogerson (1988), and it has connections with their generalization in terms of heterogeneity developed in Mulligan (2001).

The rest of the paper is organized as follows. Section 2 describes the details of the selection model and studies the efficient partial equilibrium version. Section 3 enlarges the model to general equilibrium (in particular, to include endogenous physical capital accumulation and endogenous labor-force participation), in which the labor-market results carry through, and the model performs as does a typical RBC model on aggregate consumption, aggregate investment, and GDP dynamics. Section 4 concludes.

\footnotetext{
${ }^{2}$ Carlsson, Eriksson and Gottfries (2013) find that the market tightness of local labor markets in Sweden does not affect job creation. This suggests that other margins such as labor selection may be at work.

${ }^{3}$ While this focus on one margin of the labor market (namely, selection) may seem extreme at first sight, it is similar to many search and matching papers that assume that all workers that make a contact with a firm get matched. This is the case if the matching function is interpreted as contact function (i.e., contact is endogenous, while selection is exogenous). For a further discussion of this issue see Brown, Merkl and Snower (2009).
} 


\section{The Labor Market}

There are two central features of the model. First, each newly selected worker imposes linear training costs on his employer. ${ }^{4}$ The training costs consist of a fixed component, $\gamma^{h}>0$, and an idiosyncratic component, $\varepsilon_{t}^{i}$, for newly hired individual $i$. The idiosyncratic component is revealed only when a potential worker makes contact with a firm. Very generally, it can be thought of as a "match-specific" cost. ${ }^{5}$ Each individual available to be selected for work in a given time period makes contact with one, and only one, arbitrary production unit with probability one. There is a continuum of production units, each of which is constant-returns-to-scale and homogenous in all other respects, except for the match-specific training costs that it encounters with a potential new worker.

This is the second central feature of the model: depending on his training costs encountered at a specific production unit, the potential new worker may or may not be hired. If not hired, the individual cannot "match with" or "make contact with" (we use these terms synoymously) another firm, at which he may have had a lower match-specific training cost, during the same period. This inability to re-match during a given time period is a helpful way of interpreting this friction of the model. ${ }^{6}$

From a planning perspective, it is thus efficient to hire only those individuals with sufficiently attractive characteristics. Sufficiency is characterized by an endogenous state-contingent selection threshold, $\tilde{\varepsilon}_{t}$. Because individual $i$ 's idiosyncratic characteristics are defined as a cost, he is hired only if $\varepsilon_{t}^{i} \leq \tilde{\varepsilon}_{t}$. Training costs are i.i.d. across worker-firm pairs within any given period and across time periods, with probability density function $f\left(\varepsilon_{t}\right)$. Selection occurs with endogenous probability $\eta\left(\tilde{\varepsilon}_{t}\right)$, which is the cumulative distribution function of $\varepsilon$; all searching individuals being considered for a job draw from the same distribution.

Both the fixed component of training costs $\gamma^{h}$ and the idiosyncratic component of training $\operatorname{costs} \varepsilon_{t}^{i}$ are measured in units of output, and they are incurred in only the first period of a new employment relationship. ${ }^{7}$ In contrast, each incumbent worker has zero training costs and produces stochastic output $z_{t}$ in period $t$. Newly hired worker $i$ produces output net of training costs $z_{t}-\varepsilon_{t}^{i}-\gamma^{h}$. An individual who is not selected for work instead receives an outside option of $b$

\footnotetext{
${ }^{4}$ We will interchangeably refer to "firms" and "production units" in what follows because of the linearity of the production technology and the fact that we study only efficient allocations, so the manner in which employment surpluses are split via wages in a decentralized economy does not affect the results.

${ }^{5}$ There is no traditional matching function in the model as in the Pissarides (1985) framework. One could suppose that a simple matching, or "contact," function exists in which the measure of matches equals the number of searching individuals.

${ }^{6}$ At the expense of heavier notation, we could denote the "match-specific" training cost of individual $i$ at production unit $j$ as $\varepsilon_{t}^{i j}$, which would differ from $\varepsilon_{t}^{i k}, j \neq k$. The omission of the second superscript indicates the inability to re-match during a given time period.

${ }^{7}$ Individuals who have been employed for more than one period are identical in their characteristics.
} 


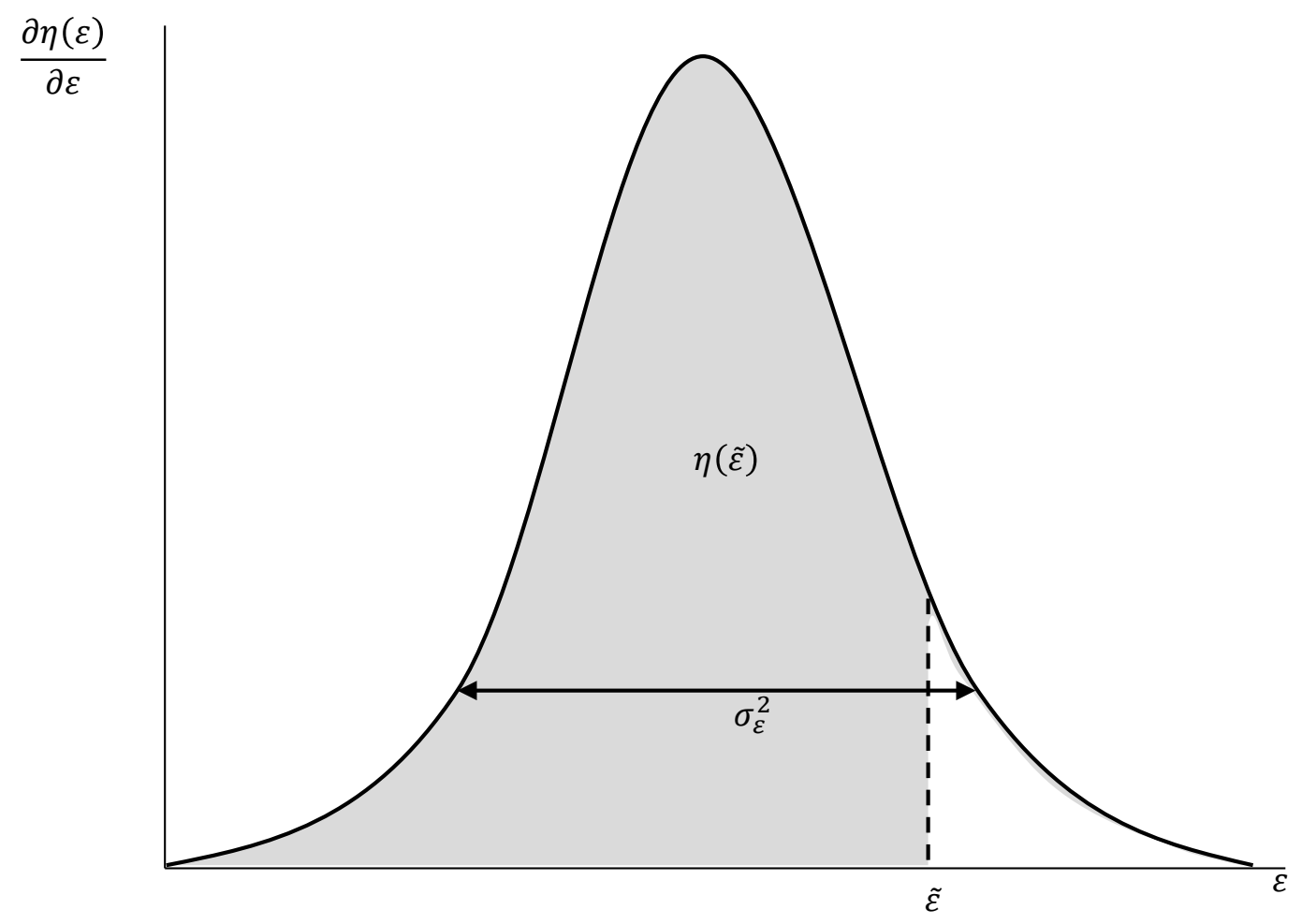

Figure 1: Illustration of the density from which the match-specific training cost of potential new hires are drawn. Higher values of $\varepsilon$ mean higher training costs. The exogenous standard deviation is denoted by $\sigma_{\varepsilon}$, the endogenously-determined selection threshold is denoted by $\tilde{\varepsilon}$, and the endogenous hiring rate (the cumulative distribution at $\tilde{\varepsilon})$ is denoted by $\eta(\tilde{\varepsilon})$ (the shaded area).

units of goods, which can be thought of interchangeably in the partial equilibrium model as home production, the utility value of leisure, or unemployment benefits.

There is no intensive margin of labor. Each unit of labor is thus to be be thought of as indivisible in the sense of Hansen (1985) and Rogerson (1988), as well as in the baseline search and matching model.

From an efficiency perspective, and defining $r$ as the net real interest rate across consecutive time periods, the dynamic surplus maximization problem for the representative production unit is thus

$$
\max E_{0} \sum_{t=0}^{\infty}\left(\frac{1}{1+r}\right)^{t}\left[z_{t} n_{t}+s_{t}\left(1-\eta\left(\tilde{\varepsilon}_{t}\right)\right) b-s_{t} \eta\left(\tilde{\varepsilon}_{t}\right)\left(\gamma^{h}+\frac{H\left(\tilde{\varepsilon}_{t}\right)}{\eta\left(\tilde{\varepsilon}_{t}\right)}\right)\right]
$$

subject to the endogenous law of motion for employment

$$
n_{t}=(1-\rho) n_{t-1}+\eta\left(\tilde{\varepsilon}_{t}\right) s_{t}
$$


and an expression defining the measure of searching individuals who are available for work during the period- $t$ selection process,

$$
s_{t}=l f p-(1-\rho) n_{t-1},
$$

in which labor force participation $(l f p)$ is an exogenous constant in this section, but is endogenous in the full general equilibrium model of Section 3.

In the surplus function (1), $H\left(\tilde{\varepsilon}_{t}\right) / \eta\left(\tilde{\varepsilon}_{t}\right)$ is the average idiosyncratic training cost for each newly selected worker, with $H\left(\tilde{\varepsilon}_{t}\right) \equiv \int_{\varepsilon \leq \tilde{\varepsilon}_{t}} \varepsilon f(\varepsilon) d \varepsilon(f(\varepsilon)$ is the probability density at $\varepsilon)$. As the law of motion (2) shows, there are "instantaneous transitions" into employment, in which new employees begin producing right away, rather than with a one-period delay. The number of individuals that receive the outside option is thus the unselected searchers, $s_{t}\left(1-\eta\left(\tilde{\varepsilon}_{t}\right)\right) .{ }^{8}$ These unselected searchers are counted as unemployed.

The law of motion (2) also shows that each individual has a fixed probability $\rho$ of separation. While heterogeneity in principle may also be empirically important for separations, the assumption of fixed $\rho$ allows the model to clearly separate heterogeneity as a basis for hiring versus for firing. ${ }^{9}$ Finally, (1) and (2) formally show that constant-returns-to-scale production of goods means it is without loss of generality to examine the problem of a single production unit that hires one worker or that hires many workers. We adopt the latter setup because it easily fits into the full model in Section 3. Figure 2 summarizes the model timing.

\section{$2.1 \quad$ Efficient Selection}

The state-contingent first-order conditions of the surplus maximization problem with respect to $n_{t}$ and $\tilde{\varepsilon}_{t}$ yield the efficient selection condition

$$
\gamma^{h}+\tilde{\varepsilon}_{t}=z_{t}-b+\left(\frac{1-\rho}{1+r}\right) E_{t}\left\{H\left(\tilde{\varepsilon}_{t+1}\right)-\tilde{\varepsilon}_{t+1} \eta\left(\tilde{\varepsilon}_{t+1}\right)+\gamma^{h}+\tilde{\varepsilon}_{t+1}\right\}
$$

which is the central result of the paper. ${ }^{10}$ This intertemporal condition characterizes the dynamics of $\tilde{\varepsilon}_{t}$ and hence the dynamics of $n_{t}$. It corresponds to the matching model's vacancy-creation (or job-creation) condition; it also corresponds to the real business cycle (RBC) model's Euler equation for efficient capital accumulation. Even though the partial equilibrium version of the model does not have "physical capital" in the strict RBC sense, the creation of an employment match is an investment activity that yields a long-lasting asset. The selection condition is the intuitive heart

\footnotetext{
${ }^{8}$ This is the timing assumption in the labor selection model of Lechthaler, Merkl, and Snower (2010), and it has also become a standard in models featuring labor matching frictions, so we adopt it for comparability. The main results do not depend on the particular timing of labor transitions, however.

${ }^{9}$ The seminal theoretical reference in the matching literature for endogenous separation is Mortensen and Pissarides (1994).

${ }^{10}$ Its derivation appears in Appendix A.
} 


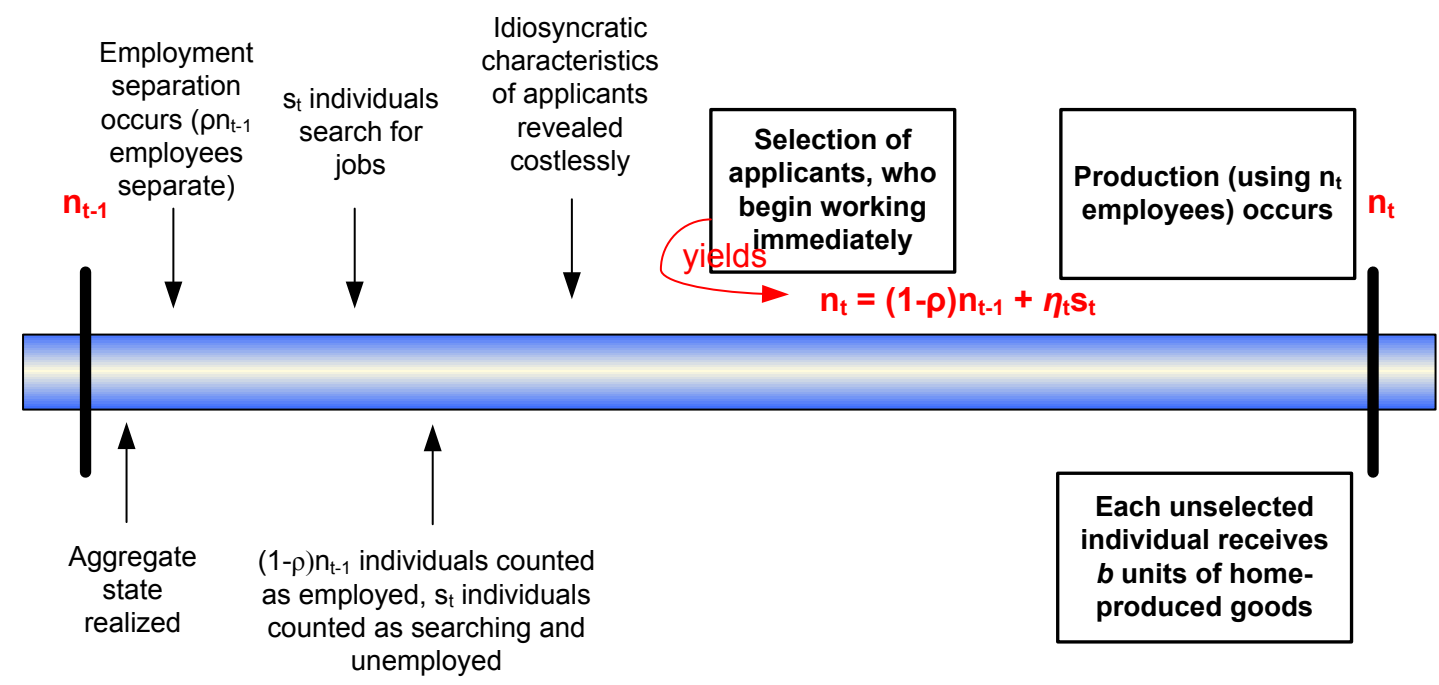

Period t-1

Period $\mathbf{t}$

Period $\mathrm{t}+1$

Figure 2: Timing of events in labor market.

of the model, so it is worth examining further.

To build intuition, first consider the stark case of $\rho=1$, which makes employment a one-period, though not a frictionless, phenomenon. This yields a simple version of the selection condition, $\gamma^{h}+\tilde{\varepsilon}_{t}=z_{t}-b$, which implies that the elasticity of the selection threshold with respect to aggregate productivity along the business cycle is

$$
\frac{\partial \ln \tilde{\varepsilon}_{t}}{\partial \ln z_{t}}=\frac{z_{t}}{\tilde{\varepsilon}_{t}}
$$

Given that $\gamma^{h}$ is the average fixed training cost for every new hire, the distribution of $\varepsilon_{t}$ without loss of generality can be centered around zero.

We assume a simple uniform $U[-x, x]$ distribution of idiosyncratic training costs to illustrate the main point. For comparability with the numerical analysis below, we set the standard deviation of training costs to be 0.4 - that is, $x=0.7$ in this example. The maximum value that the endogenous selection threshold could possibly be in this example is the upper end of the support, $\tilde{\varepsilon}=x=0.7$, which is the case of all workers being hired (i.e., nobody is selected out). In this case (and normalizing $z_{t}=1$ ), $\frac{\partial \ln \tilde{\varepsilon}_{t}}{\partial \ln z_{t}}=1.43$. For any smaller value of the threshold $\tilde{\varepsilon}$, the elasticity of its fluctuations with respect to $z_{t}$ is even larger. But this result is just for the case of $\rho=1$.

With the more realistic $\rho<1$, an explicit elasticity can be derived only in the steady state. From the deterministic steady state version of (4), the elasticity of (steady-state) $\tilde{\varepsilon}$ with respect to (steady-state) $z$ is

$$
\frac{\partial \ln \tilde{\varepsilon}}{\partial \ln z}=\left(\frac{z}{\tilde{\varepsilon}}\right)\left(\frac{1+r}{r+\rho+(1-\rho) \eta(\tilde{\varepsilon})}\right)
$$


Two observations based on (6) are important. First, the second term on the right-hand side is larger than unity given that $\rho \in[0,1]$ and $\eta(\tilde{\varepsilon}) \in[0,1]$. This elasticity is thus even larger than the one-period elasticity in (5). Second, the sensitivity of the threshold $\tilde{\varepsilon}$ to aggregate productivity does not directly depend on $b$ and hence does not depend directly on the social surplus $z-b .{ }^{11}$ Similarly, the sensitivity does not depend on the average level of training costs $\gamma^{h}{ }^{12}$ Local fluctuations of the threshold training cost around the steady state are thus insensitive to the size of the social surplus and can be large. This is in sharp contrast to an efficient version of a labor search and matching model, as demonstrated by many and summarized in, say, Rogerson and Shimer (2011).

It is not fluctuations of just the selection threshold, but, importantly, also of the hiring rate $\eta\left(\tilde{\varepsilon}_{t}\right)$ that are powerful. Continuing with the $U[-0.7,0.7]$ example, the hiring rate is $\eta(\tilde{\varepsilon})=\frac{\tilde{\varepsilon}+0.7}{2 \cdot 0.7}$, and the $\mathrm{PDF}$ is $f(\varepsilon)=\frac{1}{2 \cdot 0.7}$. As in numerical simulations later, we set $\rho=0.1, r=0.01$ and calibrate the hiring rate to 0.58 . The elasticity of the hiring rate with respect to aggregate productivity around the steady state is thus

$$
\begin{aligned}
\frac{\partial \ln \eta(\tilde{\varepsilon})}{\partial \ln z} & =\frac{\partial \ln \eta(\tilde{\varepsilon})}{\partial \ln \tilde{\varepsilon}} \frac{\partial \ln \tilde{\varepsilon}}{\partial \ln z} \\
& =\frac{\eta^{\prime}(\tilde{\varepsilon})}{\eta(\tilde{\varepsilon})}\left(\frac{z}{\tilde{\varepsilon}}\right)\left(\frac{1+r}{r+\rho+(1-\rho) \eta(\tilde{\varepsilon})}\right) \\
& =\frac{1}{0.58} \cdot 1.43 \cdot 1.60 \\
& =3.94
\end{aligned}
$$

which is obviously a lot larger than the theoretically identically zero elasticity of an efficient version of the labor matching model as described in Rogerson and Shimer (2011).

From an empirical perspective, this elasticity turns out to be remarkably similar to that found in the data, even though we are not targeting this value. Using data constructed for the period 1951:Q1 - 2007:Q1, and measuring the cyclical component after HP detrending with a smoothing parameter of 1,600 , the empirical value of the elasticity of the hiring rate with respect to aggregate

\footnotetext{
${ }^{11}$ At higher-order approximations, the sensitivity of $\tilde{\varepsilon}$ to productivity shocks in general will depend on $b$ because $\tilde{\varepsilon}$ is fundamentally a function of $b$ (albeit a nonlinear one) through the selection condition. But these effects are indirect (i.e., of second- and higher order), unlike the effects of small surpluses in matching models, which have first-order effects. The latter effect can be seen in, for example, Hagedorn and Manovskii (2008, p. 1695), which highlights that the social surplus $z-b$ does strongly affect the matching model's dynamics, even though it does not affect the selection model's dynamics.

${ }^{12}$ However, there is an indirect effect that larger $\gamma^{h}$ and larger $b$ reduce the steady state value of $\eta(\tilde{\varepsilon})$, which may lead to larger log-deviations for a given absolute deviation. Because the long-run selection rate in the model is calibrated to the empirically relevant long-run hiring rate in U.S. data in all partial equilibrium and general equilibrium simulations below, this indirect effect is excluded.
} 
productivity is $2.9 .{ }^{13,14}$

The main point is that, for an analytically simple distribution of heterogeneity, amplification of aggregate productivity fluctuations into efficient labor market dynamics are locally very powerful.

\subsection{Quantitative Results}

Solutions for richer distributions, even in partial equilibrium, require quantitative solution. The solution is state-contingent allocations $\left\{\tilde{\varepsilon}_{t}, n_{t}\right\}_{t=0}^{\infty}$ characterized by the law of motion for employment (2) and the efficient selection condition (4), taking as given the initial employment stock $n_{-1}$ and a law of motion for exogenous aggregate productivity. The latter is governed by a standard $\mathrm{AR}(1)$ process, $\ln z_{t}=\rho_{z} \ln z_{t-1}+\epsilon_{t}^{z}$, with innovations $\epsilon_{t}^{z}$ distributed $N\left(0, \sigma_{\epsilon^{z}}^{2}\right)$, and standard parameter values $\rho_{z}=0.95$ and $\sigma_{\epsilon^{z}}=0.01$. The initial employment stock $n_{-1}$ is (endogenously) set equal to the long-run steady-state value of $n$ that emerges from (2) and (4).

The frequency of the full general equilibrium model in Section 3 is quarterly, so we set a real quarterly interest rate $(1+r)^{-1}=0.99$ in the partial equilibrium version. The separation rate is set to $\rho=0.1$, consistent with the average quarterly job-destruction rate in the U.S. The interchangeably interpreted home production value/value of leisure/unemployment benefit $b$ is chosen to be 71 percent of aggregate productivity, which means $b=0.71$ given the usual normalization of long-run productivity $\ln z=0$. The share of individuals that participate in the labor market is exogenously normalized to $l f p=0.74$ in this partial equilibrium section; it will be endogenized in the general equilibrium section (this long-run participation value is taken from the empirical analysis of Veracierto (2008)).

The remaining parameters are the average training cost $\gamma^{h}$ and the dispersion of workers' idiosyncratic ("match-specific") training costs. We discuss in further detail the calibration strategy behind these parameters and their empirical counterparts as measured by Barron, Black, and Loewenstein (1989) and Dolfin (2006) in the general equilibrium model in Section 3, only noting briefly the numerical values here. Because training costs apply only to new hires and is matchspecific, the idiosyncratic component is naturally assumed to have zero persistence. ${ }^{15}$ The distri-

\footnotetext{
${ }^{13}$ This elasticity corresponds to the coefficient obtained in an OLS regression of log job finding probability on log aggregate productivity. The data on unemployment, vacancies, output and productivity were downloaded from the webpage of Pascal Michaillat (https://sites.google.com/site/pmichaillat/) and correspond to the quarterly average of the series compiled by Michaillat from underlying BLS and JOLTS/Conference Board data. The quarterly job-finding probability constructed from underlying BLS data by Shimer was downloaded from his research webpage (https://sites.google.com/site/robertshimer/research/flows). Both Michaillat (2012) and Shimer (2005) use HP smoothing parameter $10^{5}$ - neither reports this particular elasticity of the hiring rate with respect to aggregate productivity.

${ }^{14}$ We are grateful to Ana Lariau for collecting these data in a way consistent with both the Shimer and Michailliat analyses and for computing the cyclical elasticities.

${ }^{15}$ The average training cost $\gamma^{h}$ also of course applies only to new hires, but there is nothing match-specific about it.
} 


\begin{tabular}{lrrrr}
\hline \hline & $z$ & $n$ & $u e$ & $\eta(\tilde{\varepsilon})$ \\
\hline \multicolumn{4}{c}{ Efficient partial equilibrium allocation } \\
Mean & 1 & 0.69 & 0.05 & 0.58 \\
Volatility (SD\%) & 1.30 & 0.50 & 6.85 & 3.46 \\
Autocorrelation & 0.70 & 0.87 & 0.87 & 0.76 \\
\hline
\end{tabular}

Table 1: Labor market fluctuations driven by aggregate productivity shocks. Second moments computed from cyclical components of HP-filtered simulated data using standard quarterly smoothing parameter 1,600.

bution from which idiosyncratic training costs are drawn is assumed to be lognormal, $\ln N\left(\mu, \sigma_{\varepsilon}^{2}\right)$. Given $\gamma^{h}>0$, we set $\mu=0$. The parameter $\sigma_{\varepsilon}$ is chosen to obtain a standard deviation of matchspecific training costs in the cross section of 0.4. Given these distributional parameters and a target for the steady-state selection rate $\eta(\tilde{\varepsilon})$ of 0.58 , we set the value of the fixed component of training costs to $\gamma^{h}=0.29 .^{16}$

Table 1 presents simulation-based results. ${ }^{17}$ The main results appear in the second row. The volatility of unemployment (the unemployed are the individuals $s_{t}$ hoping to be matched in period $t$ ) relative to that of productivity is over five, well within the empirical band of five to ten documented in the data (see, for example, Hornstein, Krusell, and Violante (2005), Table 1). The volatility of the hiring rate is about 3.5 , which is roughly half the value of 8.3 that we compute using quarterly data with an HP filter smoothing parameter of $1,600 .^{18}$ While lower than its empirical counterpart, we emphasize that an efficient version of the search and matching model generates zero volatility when driven by aggregate TFP shocks.

It is useful to establish these results in the simplest model possible because they establish that the heart of the model is the selection decision and the fluctuations induced in it by productivity shocks. The underlying intuition for the strong amplification effect in the model is that aggregate productivity affects the present value of new employment relationships in the efficient allocation. In contrast, the efficient allocation of the standard matching model displays zero volatility following an aggregate productivity shock (as noted above, see Rogerson and Shimer (2011) or, alternatively, Arseneau and Chugh (2012)).

Figure 3 qualitatively illustrates the social planner's decision problem. The horizontal axis measures the possible realizations of a match-specific $\varepsilon_{t}^{i}$. The vertical axis measures, for a particular

\footnotetext{
${ }^{16}$ The strategy for calibrating the general equilibrium version in Section 3 is the same, but the specific parameter values will differ due to the endogeneity of the aggregate physical capital stock and of labor force participation.

${ }^{17}$ Quantitative results are obtained through first-order approximation.

${ }^{18} \mathrm{~A}$ few remarks are worth making. First, we use the quarterly job-finding probability data available at Shimer's research site: https://sites.google.com/site/robertshimer/research/flows. Second, we use the typical quarterly 1,600 smoothing parameter in the HP filter, rather than a smoothing parameter of $10^{5}$ used in Shimer (2005) and Rogerson and Shimer (2011). While the impression of high empirical volatility of the hiring rate is made by either filtering parameter, our computed volatility of 8.3 is a bit lower than their measure of about 11.8. Third, in our model, the "hiring rate" by a firm of an individual is identical to the "job-finding rate" due to the lack of a matching friction.
} 


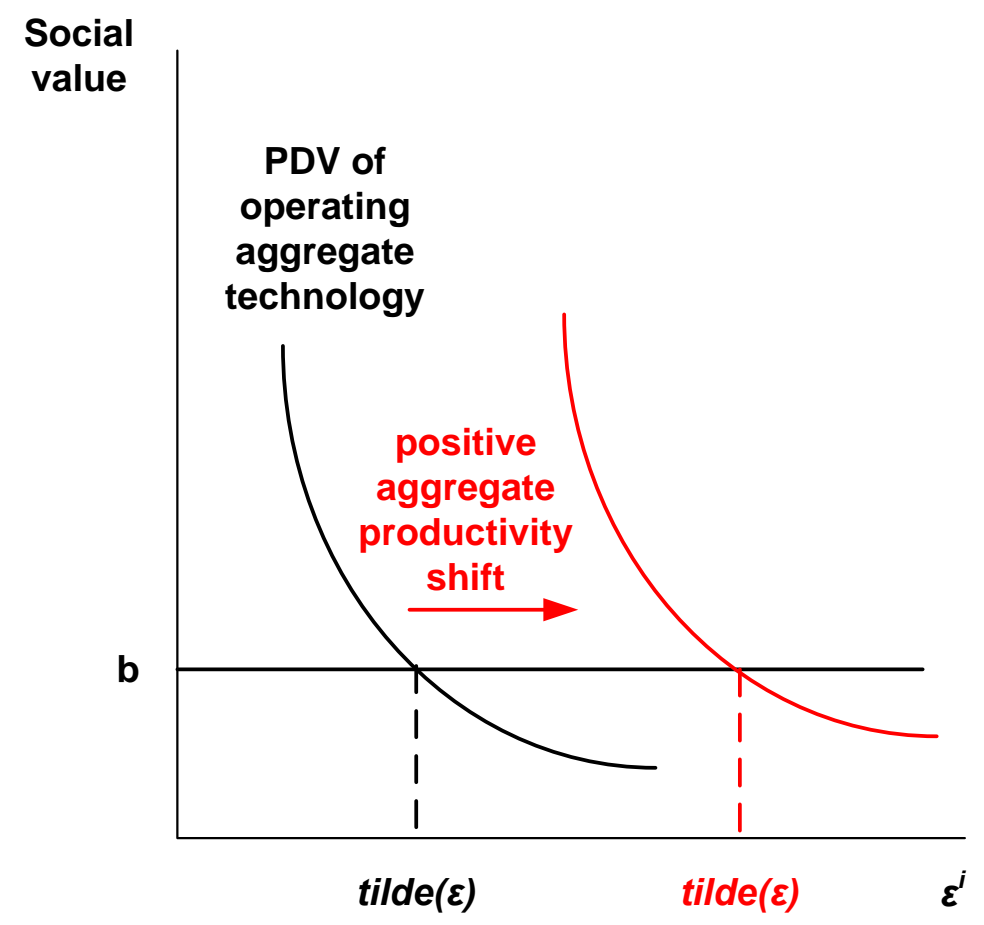

Figure 3: Shift of selection condition due to exogenous aggregate TFP shock.

match-specific realization of $\varepsilon^{i}$, the present discounted value (PDV) of operating the aggregate technology $z_{t}$ (net of $b$ ), which is homogenous across all workers. The present value of production using the aggregate technology is relevant because of the training costs that must be incurred for each new worker. It is socially wasteful to begin production if this present value is smaller than $b$, and it is socially optimal if larger than $b$. The intersection of $b$ and the downward-sloping PDV function defines the efficient cutoff point $\tilde{\varepsilon}$ for this net social value. All match-specific pairs with $\varepsilon^{i}<\tilde{\varepsilon}$ are selected by the social planner to operate the aggregate production technology for the $\frac{1}{1-\rho}$ periods that, on average, the productive unit will last; all match-specific pairs with $\varepsilon^{i} \geq \tilde{\varepsilon}$ will not be selected and will be made available the following period to possibly be selected.

As Figure 3 shows, a positive aggregate technology shock increases the average expected present value of a worker, and it is thus optimal to hire more individuals even though they are more costly to train. Stated equivalently, the selection threshold $\tilde{\varepsilon}$ loosens (tightens) following a positive (negative) TFP shock. In terms of the density illustrated in Figure 1, the selection probability increases a lot if there is a large mass of individuals between the old and the new selection thresholds.

We now show that the intuition and these main results carry over to the general equilibrium version of the model studied in Section 3. 


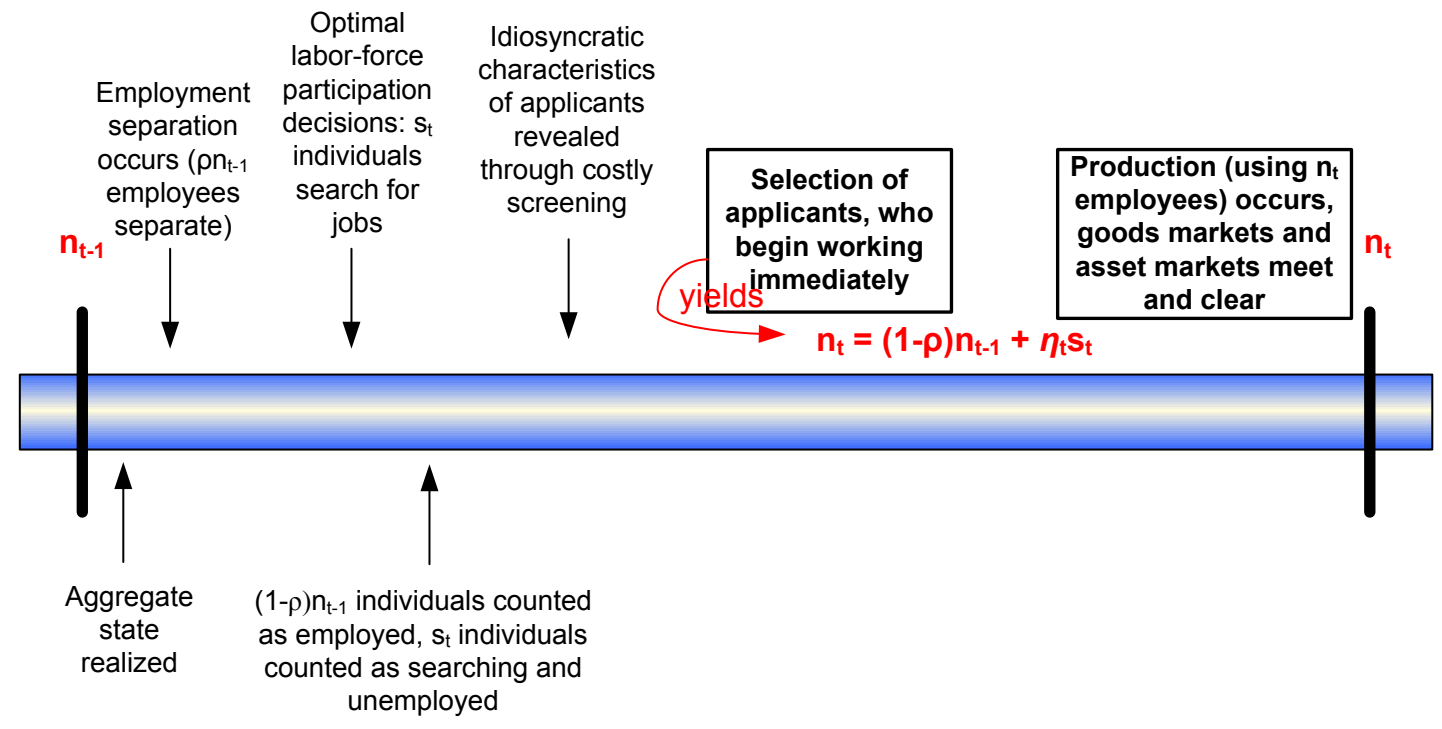

Period t-1

Period $\mathbf{t}$

Period $\mathrm{t}+1$

Figure 4: Timing of events.

\section{$3 \quad$ Efficiency and Fluctuations in General Equilibrium}

We embed the simple model above into a general equilibrium structure to show that the amplification effects carry over with little change. Figure 4 displays the timing of events in general equilibrium.

\subsection{Preferences}

As in the partial equilibrium model, there is a measure one of individuals in the economy. However, in this extended model, individuals may be in one of three labor-market states: employed, not working but searching for employment, or outside the labor force. Three labor-market states allow for broader generality of the efficiency results, but all results could be obtained by assuming individuals were either only employed or searching for employment, just as in the partial equilibrium setup. Regardless of labor-market status, each individual has full consumption insurance, which is modeled by assuming a representative household that pools income and shares consumption equally amongst all individuals. This "large household" assumption is a tractable and often-used way of modeling perfect consumption-risk insurance and is standard in the DSGE literature.

The representative household has lifetime expected utility function

$$
E_{0} \sum_{t=0}^{\infty} \beta^{t}\left[u\left(c_{t}\right)-v\left(n_{t}+\left(1-\eta_{t}\right) s_{t}\right)\right] .
$$


The subjective discount factor is $\beta \equiv(1+r)^{-1}$, the function $u($.$) is a standard strictly-increasing and$ strictly-concave subutility function over consumption, and the function $v($.$) is strictly increasing and$ strictly convex in the size of the labor force. The convexity of $v($.$) at the level of the representative$ household can be shown in exactly the same way as in Mulligan (2001), with individual-level heterogeneity of the disutility of indivisible units of labor. Thus, $v($.$) can be flexibly parameterized,$ rather than displaying quasi-linearity. ${ }^{19}$ The measure of individuals in the labor force is endogenous, which is not the case in the partial equilibrium model of Section 2, but has become fairly common in the recent DSGE matching literature. ${ }^{20}$ For intuition and because it facilitates analogy with both the RBC model and the basic matching model, it will be helpful to interpret the measure $1-l f p_{t}$ of individuals outside the labor force as enjoying leisure. We thus use the terms leisure and non-participation interchangeably, or, respectively, labor supply and labor force participation interchangeably.

\subsection{Resource Use}

Goods production employs both labor and physical capital, and the goods resource constraint at the aggregate level is

$$
c_{t}+k_{t+1}-(1-\delta) k_{t}=z_{t} f\left(k_{t}, n_{t}\right)-s_{t} \eta\left(\tilde{\varepsilon}_{t}\right)\left(\gamma^{h}+\frac{H\left(\tilde{\varepsilon}_{t}\right)}{\eta\left(\tilde{\varepsilon}_{t}\right)}\right)+s_{t}\left(1-\eta\left(\tilde{\varepsilon}_{t}\right)\right) b
$$

in which $k_{t}$ denotes the beginning of period capital stock, $\delta$ denotes its one-period depreciation rate, $f(k, n)$ is the aggregate constant-returns-to-scale production function, and, for simplicity, the " $b$ " goods are viewed as indistinguishable from formal-sector goods. The evolution of aggregate employment continues to be described by

$$
n_{t}=(1-\rho) n_{t-1}+\eta\left(\tilde{\varepsilon}_{t}\right) s_{t}
$$

with $n_{t}$ and $s_{t}$ now interpreted as economy-wide measures.

\subsection{Efficient Allocations}

Efficient allocations $\left\{c_{t}, k_{t+1}, s_{t}, \tilde{\varepsilon}_{t}, n_{t}\right\}_{t=0}^{\infty}$ are characterized by five (sequences of) conditions: a labor-force participation (LFP) condition

$$
\frac{v^{\prime}\left(l f p_{t}\right)}{u^{\prime}\left(c_{t}\right)}=\tilde{\varepsilon}_{t} \eta\left(\tilde{\varepsilon}_{t}\right)-H\left(\tilde{\varepsilon}_{t}\right)+b,
$$

\footnotetext{
${ }^{19}$ Given the definitions presented above, we sometimes will write $v\left(l f p_{t}\right)$.

${ }^{20}$ In a variety of applications, Veracierto (2008), den Haan and Kaltenbrunner (2009), Krusell, Mukoyama, Rogerson, and Sahin (2009), Ebell (2010), Haefke and Reiter (2011), and Arseneau and Chugh (2012), among others, have introduced participation margins into matching models.
} 
a standard physical capital Euler condition

$$
u^{\prime}\left(c_{t}\right)=\beta E_{t}\left\{u^{\prime}\left(c_{t+1}\right)\left(1+z_{t+1} f_{k}\left(k_{t+1}, n_{t+1}\right)-\delta\right)\right\}
$$

a general equilibrium version of the selection condition

$$
\gamma^{h}+\tilde{\varepsilon}_{t}=z_{t} f_{n}\left(k_{t}, n_{t}\right)-b+(1-\rho) E_{t}\left\{\frac{\beta u^{\prime}\left(c_{t+1}\right)}{u^{\prime}\left(c_{t}\right)}\left[H\left(\tilde{\varepsilon}_{t+1}\right)-\tilde{\varepsilon}_{t+1} \eta\left(\tilde{\varepsilon}_{t+1}\right)+\gamma^{h}+\tilde{\varepsilon}_{t+1}\right]\right\}
$$

and conditions (9) and (10). The efficiency conditions (11), (12), and (13) are obtained by maximizing household welfare (8) subject to the technological frontier defined by the sequence of goods resource constraints (9) and laws of motion for employment (10). The formal analysis of this problem is virtually identical to that in the partial equilibrium model. ${ }^{21}$

Condition (11) is a within-period dimension of efficiency and is analogous to consumptionleisure efficiency in the RBC model. Condition (13) is an intertemporal dimension of efficiency, and it extends the partial equilibrium selection condition (4) to general equilibrium by bringing the stochastic kernel $\beta u^{\prime}\left(c_{t+1}\right) / u^{\prime}\left(c_{t}\right)$ in to replace $(1+r)^{-1}$. The stochastic kernel is defined as usual by the Euler condition (12).

\subsection{Quantitative Results}

\subsubsection{Calibration}

As in the partial equilibrium model, the model frequency is quarterly, so the subjective discount factor is set to $\beta=0.99$ and the separation rate to $\rho=0.1$. For utility, standard functional forms are used, $u\left(c_{t}\right)=\ln c_{t}$ and $v\left(l f p_{t}\right)=\frac{\kappa}{1+1 / \phi} l f p_{t}^{1+1 / \phi}$. As noted above, the function $v($.$) can$ feature curvature, rather than strict linearity, in the same way as described in Mulligan (2001). The parameter $\phi$ is the elasticity of labor-force participation with respect to the real wage, which is set to $\phi=0.18$ following Arseneau and Chugh's (2012) calibration of a matching model with endogenous participation fit to U.S. data. The scale parameter is set to $\kappa=5.98$ to deliver a steadystate participation rate of 74 percent, the long-run U.S. empirical measure reported by Veracierto (2008).

The production function is assumed Cobb-Douglas, $f(k, n)=k^{\alpha} n^{1-\alpha}$, with the share $\alpha=0.33$. In line with Hall and Milgrom (2008) and the partial equilibrium setup in Section 2, we parameterize $b$ so that it constitutes 71 percent of the marginal product of labor. Because this is measured relative to the now endogenous marginal product of labor $f_{n}(k, n)$, the calibrated value is $b=1.54$.

To parameterize the dispersion of training costs $\sigma_{\varepsilon}$ (which is important for the dynamics of our

\footnotetext{
${ }^{21}$ The formal analysis appears in Appendix B.
} 
model, as discussed in the partial equilibrium model in Section 2), we use evidence from Barron, Black, and Loewenstein (1989, p. 5), who report that the standard deviation of training costs during a new hire's first three months of employment is 207 hours, which translates to 26 days, assuming an 8-hour workday. Calibrating this cross sectional dispersion requires setting $\sigma_{\varepsilon}=0.64$ in the general equilibrium model, which delivers, in terms of goods, a cross-sectional standard deviation of training costs of $40 \%$ of the marginal product of labor. This strategy was also the basis for the parameterization of the partial equilibrium model in Section $2 .{ }^{22}$ We also test for the robustness of our results, by targeting a standard deviation of training costs to 30 percent of the marginal product of labor and 50 percent of the marginal product of labor, which requires setting $\sigma_{\varepsilon}=0.53$ and $\sigma_{\varepsilon}=0.73$, respectively.

The distribution of random training costs is assumed to be $\operatorname{lognormal}, \ln N\left(\mu, \sigma_{\varepsilon}^{2}\right)$. The $\log$ normal distribution allows us to capture two facts: (i) the empirical cross-sectional training cost distribution in Barron, Black, and Loewenstein (1989) is skewed; (ii) no firm reports negative training costs. We normalize $\mu=0$ and set $\sigma_{\varepsilon}$ to obtain the targeted standard deviation of training costs. $^{23}$ To maintain tractability, the random training costs are assumed to have zero persistence.

The steady state selection rate is calibrated to $\eta(\tilde{\varepsilon})=0.58$ to generate an unemployment rate of 5 percent. Note that the unemployment rate is normalized by the entire population (i.e. also those who are out of the labor force). By dividing this number by the labor force participation of 0.74 , we obtain an unemployed / active population ratio of 0.068 , which corresponds to the conventionally reported unemployment rate.

The fixed training cost parameter $\gamma^{h}$ is chosen to obtain the targeted steady state selection rate. ${ }^{24}$ In the baseline calibration, we set $\gamma^{h}=2.6$. This corresponds to roughly 120 percent of a worker's quarterly marginal product of labor and is thus somewhat larger than the average training cost values measured by Barron, Black, and Loewenstein (1989). Three things are worthwhile noting. First, average training costs are unimportant for the sensitivity of our model with respect to productivity shocks. That is, just as the analytical and numerical results in the partial equilibrium version in Section 2 are not driven by large training costs, so too is the case in the general equilibrium results reported below. Second, the survey employed by Barron, Black, and Loewenstein (1989) only captures training costs, but not other fixed costs of hiring. Third, a perfect mapping between the data (that is, the actual decentralized economy) and our social planner economy is difficult (due to wages and various other rigidities in the decentralized economy).

\footnotetext{
${ }^{22}$ We assume that a quarter has $\frac{5}{7} * 90$ working days.

${ }^{23}$ The baseline quantitative value we thus set is $\sigma_{\varepsilon}=0.64$, as noted above, with robustness values $\sigma_{\varepsilon}=0.53$ and $\sigma_{\varepsilon}=0.73$. Note that $\sigma_{\varepsilon}$ is the standard deviation of the underlying normal distribution. By contrast, we set $\sigma_{\varepsilon}$ to obtain the targeted standard deviation of the lognormal distribution.

${ }^{24}$ As discussed in Section $2, \gamma^{h}$ is required to fix the steady-state level of the hiring rate, but it is not important for its elasticity with respect to aggregate productivity.
} 


\begin{tabular}{lrrrrrrrrr}
\hline \hline & \multicolumn{2}{c}{$g d p$} & $c$ & $n$ & $I$ & ue & lfp & $\eta(\tilde{\varepsilon})$ & $z$ \\
\hline & \multicolumn{7}{c}{ Efficient allocation $($ std $=0.40)$} \\
\cline { 2 - 7 } Mean & 2.09 & 1.60 & 0.69 & 0.49 & 0.05 & 0.74 & 0.58 & 1 \\
Volatility (SD\%) & 1.38 & 0.34 & 0.61 & 4.97 & 6.28 & 0.16 & 3.35 & 1.30 \\
Relative standard deviation & $(/ g d p)$ & 1 & 0.25 & 0.44 & 3.60 & 4.55 & 0.12 & 2.43 & 0.94 \\
Autocorrelation & 0.83 & 0.85 & 0.84 & 0.84 & 0.88 & 0.68 & 0.70 & 0.70 \\
Correlation with $g d p$ & 1 & 0.85 & 1 & 0.99 & -0.99 & 0.92 & 0.97 & 0.96 \\
\hline
\end{tabular}

Table 2: Aggregate fluctuations driven by aggregate productivity shocks in general equilibrium model with baseline parameterization of cross-sectional heterogeneity in training costs. Second moments computed from cyclical components of HP-filtered simulated data using standard quarterly smoothing parameter 1,600.

Finally, as in the partial equilibrium analysis in Section 2, the only source of aggregate risk remains aggregate productivity shocks, which follows the same $\operatorname{AR}(1)$ process $\ln z_{t}=\rho_{z} \ln z_{t-1}+\epsilon_{t}^{z}$, with identical parameters $\rho_{z}=0.95$ and $\sigma_{\epsilon^{z}}=0.01$.

\subsubsection{Results}

Table 2 displays results for the baseline calibration of the general equilibrium model. As in the partial equilibrium version, large and empirically realistic fluctuations of the hiring rate and (now endogenous) unemployment arise. The participation rate, which is also now endogenous, fluctuates slightly less relative to GDP fluctuations than reported by Veracierto (2008) for U.S. labor markets, and slightly less than in an efficient version of the labor search and matching framework with endogenous participation as shown in Arseneau and Chugh (2012). Importantly, the elasticity of the hiring rate with respect to TFP is 2.4 , which is a bit lower than but close to the empirical value of 2.9 calculated in Section 2.1. ${ }^{25}$ The model thus continues to perform well on labor market fluctuations. The cyclical volatilities of GDP, aggregate consumption, and gross physical investment are also consistent with U.S. data, as is the strong negative correlation of unemployment fluctuations and GDP fluctuations.

Tables 3 and 4 conduct the robustness tests for the alternative $\sigma_{\varepsilon}$ parameters for cross-sectional dispersion in training costs described above in the discussion on calibration. They both show that all of the results hold for parameterizations featuring, respectively, smaller cross-sectional dispersion in training costs and larger cross-sectional dispersion in training costs across potential new hires. The labor market results are thus driven, whether in general equilibrium or in partial equilibrium, by the main feature of the model, dispersion in training costs.

\footnotetext{
${ }^{25}$ The elasticity in the simulated baseline calibration of the model is $\rho_{\eta, z} \frac{\sigma_{\eta}}{\sigma_{z}}=0.93 \cdot \frac{3.35}{1.30}=2.4$. The endogenous $\sigma_{\eta}$ and $\sigma_{z}$ values appear in the second row of Table 2, and the endogenous simulation-based correlation $\rho_{\eta, z}=0.93$ (not displayed in the Table). This elasticity is computed in the same way in the analysis of Shimer, Michaillat, and many others, and is simply the model-based counterpart to OLS computations of empirical elasticities.
} 


\begin{tabular}{|c|c|c|c|c|c|c|c|c|}
\hline & $g d p$ & $c$ & $n$ & $I$ & $u e$ & $l f p$ & $\eta(\tilde{\varepsilon})$ & $z$ \\
\hline \multicolumn{9}{|c|}{ Efficient allocation $(s t d=0.30)$} \\
\hline Mean & 2.07 & 1.58 & 0.69 & 0.49 & 0.05 & 0.74 & 0.58 & 1 \\
\hline Volatility (SD\%) & 1.37 & 0.32 & 0.70 & 4.95 & 7.46 & 0.17 & 3.97 & 1.30 \\
\hline Relative standard deviation $(/ g d p)$ & 1 & 0.23 & 0.51 & 3.62 & 5.46 & 0.12 & 2.91 & 0.95 \\
\hline Autocorrelation & 0.85 & 0.86 & 0.84 & 0.86 & 0.87 & 0.68 & 0.69 & 0.71 \\
\hline Correlation with $g d p$ & 1 & 0.82 & 1.00 & 0.99 & -1.00 & 0.89 & 0.95 & 0.94 \\
\hline
\end{tabular}

Table 3: Aggregate fluctuations driven by aggregate productivity shocks in general equilibrium model with small cross-sectional heterogeneity in training costs. Second moments computed from cyclical components of HP-filtered simulated data using standard quarterly smoothing parameter 1,600.

\begin{tabular}{|c|c|c|c|c|c|c|c|c|}
\hline & $\overline{g d p}$ & $c$ & $n$ & $I$ & $u e$ & lfp & $\eta(\tilde{\varepsilon})$ & $z$ \\
\hline \multicolumn{9}{|c|}{ Efficient allocation $(s t d=0.50)$} \\
\hline Mean & 2.11 & 1.62 & 0.69 & 0.49 & 0.05 & 0.74 & 0.58 & 1 \\
\hline Volatility (SD\%) & 1.39 & 0.35 & 0.56 & 5.01 & 5.55 & 0.16 & 2.97 & 1.30 \\
\hline Relative standard deviation $(/ g d p)$ & 1 & 0.25 & 0.40 & 3.60 & 3.99 & 0.12 & 2.14 & 0.94 \\
\hline Autocorrelation & 0.81 & 0.84 & 0.84 & 0.82 & 0.88 & 0.69 & 0.70 & 0.71 \\
\hline Correlation with $g d p$ & 1 & 0.86 & 1.00 & 0.99 & -0.98 & 0.92 & 0.98 & 0.97 \\
\hline
\end{tabular}

Table 4: Aggregate fluctuations driven by aggregate productivity shocks in general equilibrium model with large cross-sectional heterogeneity in training costs. Second moments computed from cyclical components of HP-filtered simulated data using standard quarterly smoothing parameter 1,600.

\section{Conclusion}

We have proposed a simple labor-selection model, based on the idea that firms select workers from a pool of applicants. We have solved the social planner problem of this economy, both in partial and in general equilibrium. In both cases, our model generates realistic business cycle statistics, most importantly strong amplification effects of the hiring rate and unemployment. This is in sharp contrast to the efficient version of the search and matching framework.

This paper is the starting point for a variety of new questions. Decentralization of efficiency is certainly an interesting issue. As search and matching models, our framework generates a bilateral monopoly between workers and firms. Thus, surpluses can be split and there is room for bargaining. However, we show in an working paper version that Nash bargaining cannot decentralize the social planner solution. ${ }^{26}$

By adding match-specific shocks for incumbent workers and thereby generating endogenous separations, our framework is a natural framework for the analysis of frictional wage dispersion. Search models (without on-the job-search) have problems to replicate a sufficient degree of wage dispersion (Hornstein, Krusell and Violante (2011)). Our model may shed new light on this issue.

In addition, the primitives in our proposed framework are observable. While it is impossible

\footnotetext{
${ }^{26}$ The most recent version of this working paper is from February 2011, and is available at www.skchugh.com/research.
} 
to observe the matching function directly, it is possible to provide survey evidence on training costs (although the existing evidence is somewhat scarce). Thus, this allows a tighter connection of micro-evidence on training costs and macro-modeling. The dispersion of training costs may for example have shifted over time due to technological advances. Further microeconomic evidence would generate testable assumptions for macroeconomic dynamics. 


\section{References}

Arseneau, David M. and Sanjay K. Chugh. 2012. "Tax Smoothing in Frictional Labor Markets." Journal of Political Economy, Vol. 120, pp. 926-985.

Barron, John M., John Bishop, and William C. Dunkelberg. 1985. "Employer Search: The Interviewing and Hiring of New Employees." Review of Economics and Statistics, Vol. 67, pp. $43-52$.

Barron, John M., Dan A. Black, and Mark A. Loewenstein. 1989. "Job Matching and On-the-Job Training." Journal of Labor Economics, Vol. XX, pp. 1-19.

Brown, Alessio, Christian Merkl and Dennis Snower. 2009. "An Incentive Theory of Matching." Kiel Working Paper 1512.

Christiano, Lawrence J., Mathias Trabandt, and Karl Walentin. 2010. "Involuntary Unemployment and the Business Cycle.” European Central Bank Working Paper 1202.

Carlsson, Mikael, Stefan Eriksson and Nils Gottfries. 2013. "Product Market Imperfections and Employment Dynamics." Oxford Economic Papers, Vol. 65(2), pp. 447-470.

Chugh, Sanjay K. And Christian Merkl. 2011. "Efficiency in a Model of Labor Selection." Kiel Institute for the World Economy, Working Paper 1684.

Davis, Steven J., R. Jason Faberman, and John C. Haltiwanger. 2013. "The EstablishmentLevel Behavior of Vacancies and Hiring." Quarterly Journal of Economics, Vol. 127, pp. xx-xx. 90/ 482-498.

Dolfin, SARAh. 2006. "An Examination of Firms' Employment Costs." Applied Economics, Vol. 38, pp. 861-878.

Ebell, Monique. 2010. "On the Cyclicality of Unemployment: Resurrecting the Participation Margin." Humboldt University.

Faia, Ester, Wolfgang Lechthaler, and Christian Merkl. 2009. "Labor Turnover Costs, Workers' Heterogeneity, and Optimal Monetary Policy." IZA Discussion Paper, No. 4322.

GaLi, Jordi. 2011. "The Return of the Wage Phillips Curve." Journal of the European Economic Association, Vol. 9, pp. 431-461.

Gali, Jordi, Frank Smets, and Rafael Wouters. 2012. "Unemployment in an Estimated New Keynesian Model." NBER Macroeconomics Annual 2011.

Haefke, Christian and Michael Reiter. 2011. "What Do Participation Fluctuations Tell Us About Labor Supply Elasticities?.” IZA Discussion Papers, No. 6039

Hagedorn, Marcus, and Iouri Manovskir. 2008. "The Cyclical Behavior of Equilibrium Unemployment and Vacancies Revisited." American Economic Review, Vol. 98, pp. 1692-1706.

Hall, Robert E and Paul R. Milgrom. 2008. "The Limited Influence of Unemployment on the Wage Bargain." American Economic Review, Vol. 98, pp. 1654-1674. 
Hansen, Gary D. 1985. "Indivisible Labor and the Business Cycle." Journal of Monetary Economics, Vol. 16, pp. 309-327.

Hornstein, Andreas, Per Krusell, and Giovanni Violante. 2005. "Unemployment and Vacancy Fluctuations in the Matching Model: Inspecting the Mechanism." Federal Reserve Bank of Richmond Economic Quarterly, Vol. 91, pp. 19-51.

Lechthaler, Wolfgang, Christian Merkl, And Dennis J. Snower. 2010. "Monetary Persistence and the Labor Market: A New Perspective." Journal of Economic Dynamics and Control, Vol. 34, pp. 968-983.

Krusell, Per, Toshihiko Mukoyama, Richard Rogerson, and Aysegul Sahin. 2009. "Labor Supply in a Frictional Labor Market." Princeton University.

Mortensen, Dale T., And Christopher A. Pissarides. 1994. "Job Creation and Job Destruction in the Theory of Unemployment." Review of Economic Studies, Vol. 61, pp. 397415.

Mulligan, Casey B. 2001. "Aggregate Implications of Indivisible Labor." The B.E. Journals in Macroeconomics: Advances in Macroeconomics, Vol. 1, pp. 1-33.

Pissarides, Christopher A. 1985. "Short-Run Equilibrium Dynamics of Unemployment, Vacancies, and Real Wages." American Economic Review, Vol. 75, pp. 676-690.

Rogerson, Richard. 1988. "Indivisible Labor, Lotteries and Equilibrium." Journal of Monetary Economics, Vol. 21, pp. 3-16.

Rogerson, Richard And Robert Shimer. 2011. "Search in Macroeconomic Models of the Labor Market. In Handbook of Labor Economics, edited by Orley Ashenfelter and David Card, Vol. 4B. Elsevier.

Shimer, RoBert. 2005. "The Cyclical Behavior of Equilibrium Unemployment and Vacancies." American Economic Review, Vol. 95, pp. 25-49.

Veracierto, Marcelo. 2008. "On the Cyclical Behavior of Employment, Unemployment and Labor Force Participation." Journal of Monetary Economics, Vol. 55, pp. 1143-1157. 829-849. 


\section{A Partial Equilibrium Model}

The social planner optimization problem is

$$
\max E_{0} \sum_{t=0}^{\infty}\left(\frac{1}{1+r}\right)^{t}\left[z_{t} n_{t}+s_{t}\left(1-\eta\left(\tilde{\varepsilon}_{t}\right)\right) b-s_{t} \eta\left(\tilde{\varepsilon}_{t}\right)\left(\gamma^{h}+\frac{H\left(\tilde{\varepsilon}_{t}\right)}{\eta\left(\tilde{\varepsilon}_{t}\right)}\right)\right]
$$

subject to the endogenous law of motion for employment

$$
n_{t}=(1-\rho) n_{t-1}+\eta\left(\tilde{\varepsilon}_{t}\right)\left(l f p-(1-\rho) n_{t-1}\right),
$$

in which $l f p$ is an exogenous labor force participation rate, and the initial condition $n_{-1}$ and the exogenous law of motion for aggregate productivity are taken as given.

The social planner takes into account the dependence of the hiring rate and the average operating cost of a newly-selected worker on the threshold $\tilde{\varepsilon}_{t}$, which is made explicit in the notation here. Given that $\eta\left(\tilde{\varepsilon}_{t}\right) \equiv \int_{\varepsilon \leq \tilde{\varepsilon}_{t}} \eta^{\prime}(\varepsilon) d \varepsilon$ and $H\left(\tilde{\varepsilon}_{t}\right) \equiv \int_{\varepsilon \leq \tilde{\varepsilon}_{t}} \varepsilon \eta^{\prime}(\varepsilon) d \varepsilon$, we have $H^{\prime}\left(\tilde{\varepsilon}_{t}\right)=\tilde{\varepsilon}_{t} \eta^{\prime}\left(\tilde{\varepsilon}_{t}\right)$, by the Fundamental Theorem of Calculus.

Let $\mu_{t}$ denote the Lagrange multiplier. The first-order conditions of the social planner problem with respect to $n_{t}$ and $\tilde{\varepsilon}_{t}$ are, respectively,

$$
z_{t}-\mu_{t}+(1-\rho) \frac{1}{1+r} E_{t}\left\{\mu_{t+1}\left[1-\eta\left(\tilde{\varepsilon}_{t+1}\right)\right]+\left[\gamma^{h} \eta\left(\tilde{\varepsilon}_{t+1}\right)+H\left(\tilde{\varepsilon}_{t+1}\right)-\left(1-\eta\left(\tilde{\varepsilon}_{t}\right)\right) b\right]\right\}=0
$$

and

$$
-s_{t}\left[\gamma^{h} \eta^{\prime}\left(\tilde{\varepsilon}_{t}\right)+H^{\prime}\left(\tilde{\varepsilon}_{t}\right)+\eta^{\prime}\left(\tilde{\varepsilon}_{t}\right) b\right]+\mu_{t} s_{t} \eta^{\prime}\left(\tilde{\varepsilon}_{t}\right)=0
$$

Isolating the multiplier $\mu_{t}$ from (17),

$$
\mu_{t}=\gamma^{h}+\tilde{\varepsilon}_{t}+b
$$

Next, substituting expression (18) for $\mu_{t}$ (and its time $t+1$ counterpart) in (16), we have

$$
\begin{aligned}
\gamma^{h}+\tilde{\varepsilon}_{t}+b & =z_{t} \\
& +(1-\rho) \frac{1}{1+r} E_{t}\left\{u^{\prime}\left(c_{t+1}\right)\left[\gamma^{h} \eta\left(\tilde{\varepsilon}_{t+1}\right)+H\left(\tilde{\varepsilon}_{t+1}\right)-\left(1-\eta\left(\tilde{\varepsilon}_{t}\right)\right) b\right]\right\} \\
& +(1-\rho) \frac{1}{1+r} E_{t}\left\{u^{\prime}\left(c_{t+1}\right)\left[\gamma^{h}+\tilde{\varepsilon}_{t+1}+b\right]\left[1-\eta\left(\tilde{\varepsilon}_{t+1}\right)\right]\right\}
\end{aligned}
$$

Thus, the selection condition:

$$
\gamma^{h}+\tilde{\varepsilon}_{t}=z_{t}-b+(1-\rho) E_{t}\left\{\frac{1-\rho}{1+r}\left[H\left(\tilde{\varepsilon}_{t+1}\right)-\tilde{\varepsilon}_{t+1} \eta\left(\tilde{\varepsilon}_{t+1}\right)+\gamma^{h}+\tilde{\varepsilon}_{t+1}\right]\right\}
$$




\section{B General Equilibrium Model}

A social planner in this economy optimally allocates the measure one of individuals in the representative household to leisure, unemployment, and employment. There are several representations of the planning problem available: suppose that $c_{t}, k_{t+1}, l f p_{t}, n_{t}$, and $\tilde{\varepsilon}_{t}$ are the formal objects of choice. Given the accounting identities of the model, the measure of individuals available for work can thus be expressed $s_{t}=\operatorname{lf} p_{t}-(1-\rho) n_{t-1}$.

The social planner problem is to maximize lifetime expected utility of the representative household

$$
E_{0} \sum_{t=0}^{\infty} \beta^{t}\left[u\left(c_{t}\right)-v\left(l f p_{t}\right)\right]
$$

subject to the sequence of goods resource constraints

$c_{t}+k_{t+1}-(1-\delta) k_{t}=z_{t} f\left(k_{t}, n_{t}\right)-\left[l f p_{t}-(1-\rho) n_{t-1}\right] \eta\left(\tilde{\varepsilon}_{t}\right)\left(\gamma^{h}+\frac{H\left(\tilde{\varepsilon}_{t}\right)}{\eta\left(\tilde{\varepsilon}_{t}\right)}\right)+\left[l f p_{t}-(1-\rho) n_{t-1}\right]\left(1-\eta\left(\tilde{\varepsilon}_{t}\right)\right) b$,

and laws of motion for the employment stock

$$
n_{t}=(1-\rho) n_{t-1}+\left[l f p_{t}-(1-\rho) n_{t-1}\right] \eta\left(\tilde{\varepsilon}_{t}\right) .
$$

The social planner takes into account the dependence of the hiring rate and the average operating cost of a newly-selected worker on the threshold $\tilde{\varepsilon}_{t}$, which is made explicit in the notation here. Recalling that $\eta\left(\tilde{\varepsilon}_{t}\right) \equiv \int_{\varepsilon \leq \tilde{\varepsilon}_{t}} \eta^{\prime}(\varepsilon) d \varepsilon$ and $H\left(\tilde{\varepsilon}_{t}\right) \equiv \int_{\varepsilon \leq \tilde{\varepsilon}_{t}} \varepsilon \eta^{\prime}(\varepsilon) d \varepsilon$, we have $H^{\prime}\left(\tilde{\varepsilon}_{t}\right)=\tilde{\varepsilon}_{t} \eta^{\prime}\left(\tilde{\varepsilon}_{t}\right)$, by the Fundamental Theorem of Calculus.

Let $\beta^{t} \lambda_{t}$ be the Lagrange multiplier on the period- $t$ goods resource constraint, and $\beta^{t} \mu_{t}$ be the Lagrange multiplier on the period- $t$ law of motion for employment. The first-order conditions of the social planner problem with respect to $c_{t}, k_{t+1} l f p_{t}, n_{t}$, and $\tilde{\varepsilon}_{t}$ are, respectively,

$$
\begin{gathered}
u^{\prime}\left(c_{t}\right)-\lambda_{t}=0 \\
-\lambda_{t}+\beta E_{t}\left\{\lambda_{t+1}\left(1+z_{t+1} f\left(k_{t+1}, n_{t+1}\right)-\delta\right)\right\}=0 \\
-v^{\prime}\left(l f p_{t}\right)-\lambda_{t}\left[\gamma^{h} \eta\left(\tilde{\varepsilon}_{t}\right)+H\left(\tilde{\varepsilon}_{t}\right)-\left(1-\eta\left(\tilde{\varepsilon}_{t}\right)\right) b\right]+\mu_{t} \eta\left(\tilde{\varepsilon}_{t}\right)=0 \\
\lambda_{t} z_{t} f_{n}\left(k_{t}, n_{t}\right)-\mu_{t}+(1-\rho) \beta E_{t}\left\{\mu_{t+1}\left[1-\eta\left(\tilde{\varepsilon}_{t+1}\right)\right]+\lambda_{t+1}\left[\gamma^{h} \eta\left(\tilde{\varepsilon}_{t+1}\right)+H\left(\tilde{\varepsilon}_{t+1}\right)-\left(1-\eta\left(\tilde{\varepsilon}_{t}\right)\right) b\right]\right\}=0
\end{gathered}
$$

and

$$
-\lambda_{t} s_{t}\left[\gamma^{h} \eta^{\prime}\left(\tilde{\varepsilon}_{t}\right)+H^{\prime}\left(\tilde{\varepsilon}_{t}\right)+\eta^{\prime}\left(\tilde{\varepsilon}_{t}\right) b\right]+\mu_{t} s_{t} \eta^{\prime}\left(\tilde{\varepsilon}_{t}\right)=0
$$


Conditions (24) and (25) yield the standard Euler condition for physical capital accumulation,

$$
u^{\prime}\left(c_{t}\right)=\beta E_{t}\left\{u^{\prime}\left(c_{t+1}\right)\left(1+z_{t+1} f\left(k_{t+1}, n_{t+1}\right)-\delta\right)\right\}
$$

which is expression (12) in the main text.

Isolating the multiplier $\mu_{t}$ from (28),

$$
\begin{aligned}
\mu_{t} & =\frac{u^{\prime}\left(c_{t}\right)\left[\gamma^{h} \eta^{\prime}\left(\tilde{\varepsilon}_{t}\right)+H^{\prime}\left(\tilde{\varepsilon}_{t}\right)+\eta^{\prime}\left(\tilde{\varepsilon}_{t}\right) b\right]}{\eta^{\prime}\left(\tilde{\varepsilon}_{t}\right)} \\
& =u^{\prime}\left(c_{t}\right)\left[\gamma^{h}+\tilde{\varepsilon}_{t}+b\right]
\end{aligned}
$$

in which we have substituted (24). Substituting this expression for $\mu_{t}$ in (26) gives

$$
\begin{aligned}
\frac{v^{\prime}\left(l f p_{t}\right)}{u^{\prime}\left(c_{t}\right)} & =\tilde{\varepsilon}_{t} \eta\left(\tilde{\varepsilon}_{t}\right)-H\left(\tilde{\varepsilon}_{t}\right)+b \\
& =\int_{\varepsilon \leq \tilde{\varepsilon}_{t}}\left[\tilde{\varepsilon}_{t}-\varepsilon\right] f(\varepsilon) d \varepsilon+b
\end{aligned}
$$

in which the second line substitutes the definitions of $H\left(\tilde{\varepsilon}_{t}\right)$ and $\eta\left(\tilde{\varepsilon}_{t}\right)$. The term in square brackets in the integral is unambiguously positive. Expression (31) is the static efficiency condition that appears as condition (11) in the main text.

Next, substituting expression (30) for $\mu_{t}$ (and its time $t+1$ counterpart) in (27), we have

$$
\begin{aligned}
u^{\prime}\left(c_{t}\right)\left[\gamma^{h}+\tilde{\varepsilon}_{t}+b\right] & =u^{\prime}\left(c_{t}\right) z_{t} f_{n}\left(k_{t}, n_{t}\right)+(1-\rho) \beta E_{t}\left\{u^{\prime}\left(c_{t+1}\right)\left[\gamma^{h} \eta\left(\tilde{\varepsilon}_{t+1}\right)+H\left(\tilde{\varepsilon}_{t+1}\right)+\left(\gamma^{h}+\tilde{\varepsilon}_{t+1}\right)\left(1-\eta\left(\tilde{\varepsilon}_{t+1}\right)\right)\right]\right. \\
& =u^{\prime}\left(c_{t}\right) z_{t} f_{n}\left(k_{t}, n_{t}\right)+(1-\rho) \beta E_{t}\left\{u^{\prime}\left(c_{t+1}\right)\left[H\left(\tilde{\varepsilon}_{t+1}\right)-\tilde{\varepsilon}_{t+1} \eta\left(\tilde{\varepsilon}_{t+1}\right)+\gamma^{h}+\tilde{\varepsilon}_{t+1}\right]\right\}
\end{aligned}
$$

Dividing by $u^{\prime}\left(c_{t}\right)$ gives the selection condition

$$
\gamma^{h}+\tilde{\varepsilon}_{t}=z_{t} f_{n}\left(k_{t}, n_{t}\right)-b+(1-\rho) E_{t}\left\{\frac{\beta u^{\prime}\left(c_{t+1}\right)}{u^{\prime}\left(c_{t}\right)}\left[H\left(\tilde{\varepsilon}_{t+1}\right)-\tilde{\varepsilon}_{t+1} \eta\left(\tilde{\varepsilon}_{t+1}\right)+\gamma^{h}+\tilde{\varepsilon}_{t+1}\right]\right\} .
$$

